This is a self-archived final draft version of the original article. It differs from the original in pagination and typographic detail.

Matalamäki, M., Vuorinen, T., Varamäki, E. \& Sorama, K. 2017. Business growth in established companies: roles of effectuation and causation. Journal of Enterprising Culture 25 (2), 123-148. DOI: https://doi.org/10.1142/S0218495817500054

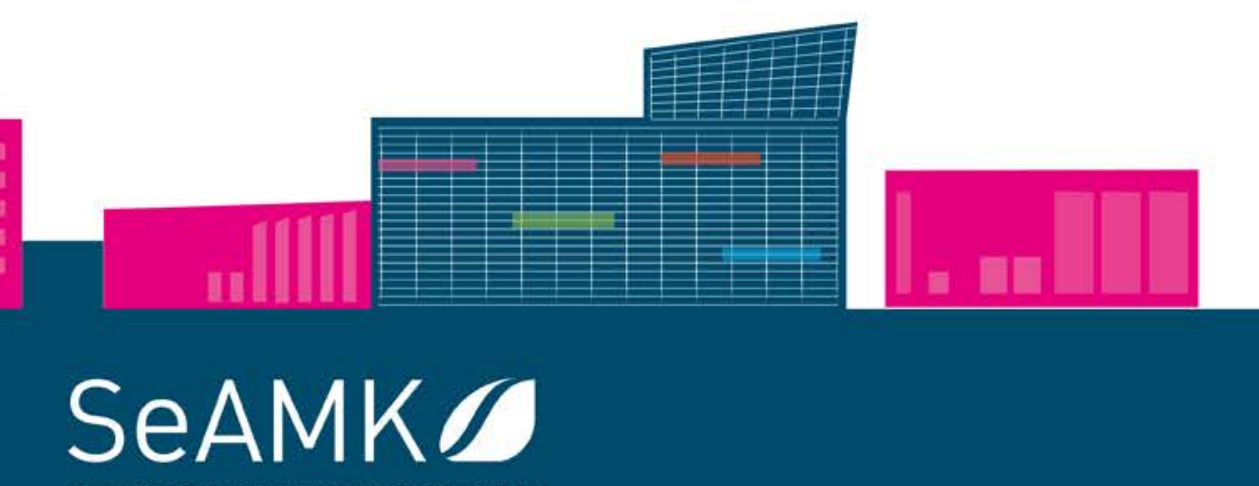




\title{
Business growth in established companies; roles of effectuation and causation
}

\begin{abstract}
This multiple case study illustrates how ten selected industrial companies have managed to accomplish rapid growth after a long period (3-5 years) of slow growth. A particular aim was to determine whether these companies grew by adapting to the situation and responding to the demands of the market with their resources (effectuation) or by following previously determined plans and proceeding towards set goals (causation). Effectuation was originally connected to the creation of new business activities and an operating model covering the early stages of an organisation's growth. However, recent studies have considered effectuation in the context of an existing business. This paper adds business growth to the context of established companies and explores the roles of effectuation and causation in their growth processes. The findings indicate the usage of both logics, but in nine of the ten companies' effectuation influences as the dominant approach. Only one of the ten studied companies can be stated to follow the operating principles of causation.
\end{abstract}

Keywords: effectuation, causation, business growth, established companies

\section{Introduction}

Business growth constitutes one of the central topics of entrepreneurship research. As interest in entrepreneurship has intensified, new theoretical perspectives have emerged explaining entrepreneurial behaviour (Leitch, Hill and Neergaard, 2010; Fisher, 2012). One of the most cited emerging theories in entrepreneurship is effectuation (Sarasvathy, 2001; Perry, Chandler and Markova, 2011; Fisher, 2012). Effectuation has been strongly connected to the early stages of the creation of an organisation and just recently introduced as logic potentially applicable to existing businesses (Berends et al., 2014; Kalinic et al., 2014; Werhahn, Mauer, Flatten and Brettel, 2015). The context of existing companies was neglected in effectuation research for many years, despite that already ten years ago Wiltbank, Dew, Read and Sarasvathy, (2006) first considered the suitability of effectuation logics in existing companies. 
This research applies effectuation theory and contrasts it to the traditional approach to entrepreneurship - causation (Sarasvathy, 2001), in the context of established companies, which have had a growth spurt after long period of slow growth. The main objective was to study what had occurred during the growth process and which factors had influenced the growth process. A particular aim was to determine whether companies grew by adapting to the logics of effectuation or by following more traditional, causational traits. There is relatively little previous literature combining a scrutiny of effectuation and business growth. In the literature review, we found seven papers, which had both concepts in the key words or title, but found no studies combining these two concepts in the context of established companies. In a past few years, the literature has focused on combining effectuation and other constructs, like innovation and internationalisation. These on the other hand, are widely seen as key sources of economic growth (Dew and Sarasvathy, 2007; Gabrielsson and Gabrielsson, 2013; Helmersson and Mattson, 2013). This research fills the gap in literature by combining effectuation and business growth and adding the context of established companies.

Effectuation and causation differ in at least five respects: 1) The use of available resources versus moving towards a specific goal, 2) controlled risk taking versus targeting maximum profit accompanied by higher risks, 3) building strategic alliances versus competitor analysis, 4) taking advantage of changes in the environment for the organisation's benefit versus taking advantage of previously acquired knowledge, and 5) aiming to influence the future versus aiming to predict the future (Sarasvathy, 2008). Chandler et al (2011) developed Sarasvathy's work by outlining four subdimensions; 1) experimentation (focus on short terms experiment to identify opportunities versus prediction of the future, 2) affordable loss versus maximization of expected returns, 3) emphasis on pre-commitments and strategic alliances to control the future versus competitive analyses to predict the future, and 4) exploitation of the environmental contingencies by remaining flexible versus exploitation pre-existing capabilities and resources (Chandler et al., 2011, 377).

This study has four key contributions. First, we expand the scope of effectuation research from its prior primary focus on new ventures and start-ups to include existing companies as a suitable context. Second, the results indicate, that established companies have the potential to take a growth leap and become growth companies, when using logics of effectuation as their dominant approach. Third, the findings strengthen the previous literature, where effectuation is considered a practical approach in turbulent and unstable business environment. Fourth, we confirm the current 
knowledge of effectuation literature, where both effectuation and causation are found to be used simultaneously in same organisation.

\section{Theoretical background}

\subsection{Effectuation and causation}

Effectuation is an emerging theoretical perspective in entrepreneurship research (Fisher, 2012; Perry et al., 2012) Effectuation theory assumes the goal of an entrepreneur is not fully known at the beginning of the entrepreneurial process. Instead, the entrepreneur utilises the resources available to meet the demands of the market in a flexible manner (Sarasvathy, 2001). A good example of effectuation is provided by a metaphor of a chef using whatever ingredients are in the store cupboard to decide which meal to cook, that is, the outcome relies on the available materials. In an alternative version of this activity, the chef has a recipe (plan) which he or she follows by acquiring the ingredients (resources) and using them to achieve the end result, set as the goal of the activity. This approach is called causation (Sarasvathy, 2001; 2008).

While effectuation is at its best in an unpredictable environment, causation is relevant in a stable operating environment. It does not work particularly well in a turbulent operating environment or in the face of constant change (Sarasvathy, 2001; Fisher, 2012; Dutta et al., 2015). Practitioners of effectuation tend to take risks only to an extent matched by the losses they are prepared to sustain, and also ensure they are capable of reacting to changes triggered by the environment. Causal logic in terms of this dimension prescribes the calculation of expected returns, and the objective will be to maximise expected returns (Brettel et al., 2012).

The causational school, which is perhaps better known as the rational planning school, is among the oldest in the strategic management sphere of thought, and contains widely cited theories such as those propounded by Ansoff (1965) and Porter (1980), which emphasise the importance of systematic analysis and integrative planning. Effectuation, on the other hand, is based on the models by Knight (1921), Weick (1979), March (1982, 1991), March and Simon (1958) and also Mintzberg (1978) and Mintzberg and McHugh (1985) questioning the efficiency of decision-making founded on systematic planning. At the core of causation lies an idea that there is a goal or objective, selected based on strategy, towards which the organisation works by acquiring the necessary 
resources (Sarasvathy, 2001). Some of the resources may be new, while others may already be available to the organisation. The benefits of this approach include the organisation being able to provide what the market demand in a cost-effective and timely manner (Sarasvathy, 2001, p. 250; Dew, Read, Sarasvathy and Wiltbank, 2009).

Recent empirical studies have found evidence that effectuation and causation can work simultaneously in the same organisation (Sitoh et al., 2014; Dutta, Gwebu and Wang 2015; Lingelbach et al., 2015; Reymen, Andries, Berends et al., 2015). The causation approach ensures that the venture stays focused and predicts what is predictable, while the effectuation counterpart allows a flexible response to changes in the operations environment (Sarasvathy, 2008; Dew et al., 2009; 2011; Fisher, 2012). Berends et al. (2014) illustrated an early form of effectuation logic, which increasingly moved towards becoming causation logic over time in their multimethod study of product innovation processes in small established manufacturing firms. Effectuation and causation are generic decision-making mechanisms that can exist simultaneously with one another and that are configured in specific ways during different phases of the process of new product creation (Van de Vrande, De Jong, Vanhaverbeke and Rochemont, 2009; Sitoh et al., 2014).

\subsection{The development of effectuation theory}

Effectuation theory seems to be at a crossroads. It has many supporters, like Fisher (2012), who believes that effectuation is one of the few viable alternative theoretical perspectives describing entrepreneurial action, and Coviello and Joseph (2012), who see effectuation as an explanation of success in new product development. There are also divergent research opinions, like that of Chiles, Bluedorn, and Gupta (2007), who find effectuation undefined and less original; and of Baron (2009), who argues that the basic tenets described in effectuation theory cannot actually exist. According to a main stream of the researchers, the heuristics of effectuation are widely acknowledged (Read, Sarasvathy, Dew, and Wiltbank 2016; Sitoh, Pan and Yu, 2014; Lingelbach et al 2015; Reymen, Andries, Berends, Mauer et al 2015; Dutta, Gwebu and Wang, 2015).

Fischer and Reuber (2011, p.15) stated that prior effectuation research scholars have identified only one variable for justifying the use of the effectuation process; expertise. Empirical results support the theory proposed by Sarasvathy (2008) that experienced entrepreneurs are more likely to use effectuation than inexperienced entrepreneurs (Sarasvathy, 2008; Dew et al., 2009; Fiet, Norton and Van Clouse, 2012). Experienced entrepreneurs aim to succeed with the available resources and only 
invest the resources they are willing to lose into a project. Companies using effectuation logic remain adaptable to changes in order to sustain progress in a rapidly changing operating environment (Sarasvathy, 2008; Dew et al., 2009).

Some of the criticism concerns the testability of the theory. There are researchers, who argue that effectuation has yet to be properly tested (Arend, Saroogh \& Burkemper, 2015). More recently, there have been attempts to develop measurement approaches for effectuation (Chandler et al., 2011; Brettel et al., 2012; Werhahn et al., 2015). Chandler et al. (2011) first developed and validated measures of causation and effectuation, proposing that effectuation is a construct with four subdimensions (experimentation, affordable loss, flexibility, and one dimension shared with the causation construct, pre-commitment). Since their paper, the research on effectuation has intensified and more empirical research has been presented.

Recent research diversifies the effectuation logic from the entrepreneurial level to the corporate context (Brettel et al., 2012). Werhahn et al. (2015) present preliminary insights into a potential relationship among the dimensions of effectual orientation, and divide subdimensions of effectual orientation to the five dimensions; means orientation, partnership orientation, affordable loss orientation, contingency orientation and control orientation. The scholars have presented empirical results of effectuation logic operating in existing companies. Kalinic et al. (2014) published a qualitative study of the internationalisation process of five existing manufacturing SMEs. Unplanned internationalisation does not necessarily involve illogical decisions; but entrepreneurs tend to follow an effectual rather than causal logic and their decisions may be based on the affordable loss principle rather than on the maximisation of expected returns (Kalinic et al., 2014). Coviello and Joseph (2012) explore how firms engage with customers during new product development. Their findings indicate that successful innovators tend to engage with customers.

Sarasvathy et al. (2014) integrates the Uppsala model with effectuation theory in an international company. Werhahn et al. (2015) takes the concept of effectuation from the individual level to the firm level in large survey study in existing companies. Svensrud and Åsvoll (2012) studied the value of effectuation processes in the innovation activity of large companies. This is in line with concepts such as corporate entrepreneurship (Jennings and Lumpkin, 1989; Kuratko, Hornsby and Goldsby, 2004) and EO (Lumpkin and Dess, 1996). 
There is a lively debate on the need for entrepreneurial action in large companies (Pongracic, 2009; Schmelter, Mauer, Borsch and Brettel, 2010). Both new and mature companies are needed to take in to consideration when expecting to create business growth. This research aims to highlight, that there is a lot of potential in existing companies. Mature companies are not in the center of the interest of the entrepreneurial discussion, when it comes to business growth. The results of this study indicate that established companies have a lot of potential to become growth companies. Maybe they ought to be in the economical discussion, as well as the new ventures and startups.

\subsection{Business growth and effectuation}

Literature on small firm growth suggests that little is yet known about the phenomenon, and conceptual development is still modest (Wiklund, Patzfelt and Shepherd, 2009). The research has mainly focused on factors preceding growth, aiming to provide an explanation for growth using factors related to the entrepreneur and entrepreneurial activities. Both firms and individuals can be entrepreneurial. The focus has been on EO (e.g. Covin and Slevin 1989; Wiklund, 1999), the company and the environment, (e.g. Davidsson, 1989; Audretsch, 1995), the size or the resources of the company, (Connor, 1991; Alvarez and Busenitz, 2001) strategic orientation (Lumpkin and Dess, 1996), or characteristics of the environment (Barney, 1991; Davidsson, Kirrchoff, Hatemi and Gustavsson 2002). Previous research has also found that small firms that are growing tend to develop profitable and expanding market niches (Storey, 1996).

Three primary research streams can be detected in the research on business growth (McKelvie and Wiklund, 2010). In the first, growth is perceived as an outcome. This stream focuses on studying the factors leading to growth, and growth is perceived as a variable dependent on these factors (Barron, 1999; Batt, 2002; Baum, Locke and Smith, 2001). The second stream is focused on the consequences of growth. In this orientation, growth is considered to be the outcome of changes in the company operations, particularly in decision-making and expertise. Growth is considered to be a variable influencing other variables (Ketchen, Thomas and Snow, 1993; Phelps et al., 2007; Short, Payne and Ketchen, 2008). The third stream focuses on the growth process itself, in which growth is perceived as neither a dependent nor an independent variable, but, instead, the focus is on the growth process that has occurred. This study can be placed in the first initial category proposed by McKelvie and Wiklund (2010); that addressing growth as an outcome. This is scrutinised through 
the lenses of effectuation and causation to obtain new insights into the phenomenon of the growth of established companies.

\section{Methods}

\subsection{Case selection}

Case companies were selected from the Voitto+ database of 6403 companies in Southern Ostrobothnia area in Western Finland. (Finland's most extensive database of financial statements, run by Asiakastieto Ltd). The area was chosen because of the regional funding of the research. The companies' financial statements were investigated to identify those that had after three years of moderate growth achieved a clear growth spurt of above 30 per cent in their turnover over a period of three years. Longitudinal data have been used in several previous cross-sectional growth studies, but the timespans usually considered have been 3-5 years (Delmar, 1997). A high growth firm is a firm with at least 10 employees initially that increases sales turnover by at least 20\% per year, over at least three years period (Parker, Storey and Witteloostuijn, 2010).

When the following selection criteria were applied: 1) an industrial company that had operated for at least five years, the list was narrowed in to 1003 companies 2) which employed at least ten employees at the starting point, but not more than 249 employees (this is the Eurostat definition for a small or medium-sized company) we found 182 companies and 3). whose operations had been profitable during this cycle, and the additional criteria, we found 31 companies suitable for target group. The additional criterion meant the likes of construction companies that had managed a large growth spurt in one year due to landing a big contract. These companies were excluded. Initial screening revealed 31 potential companies apparently suited to closer evaluation.

This study is based upon the growth of a firm is based on the most widely used empirical growth indicator in the field of entrepreneurship and small business research; sales turnover growth of the firm (Murphy, Trailer and Hill, 1996). From this point on, a further inclusion criterion was set: 5) continued growth. The selected companies had continued growing after a growth spurt, or remain on this higher level. It was decided to constrain the investigation to ten companies initially, and increase the number of informants if the authors felt the saturation point of the information was not 
achieved. In the event, it was not necessary to expand the number of informants, because the interviews were repeating the same formula.

The number of employees of the studied companies varied from 17 to 77, with the average-size of 44 employees. The annual turnover ranged from two million to eighteen million EUR (see Table 2 on the development of turnover). Four of the ten companies were family-owned. In addition, two of the companies had once been family-owned, but had a change in ownership. Three of the companies represented the metal industry and one operated in the mechanical engineering industry. Only in one of the ten companies had the rapid growth spurt resulted in part from a corporate acquisition. The remaining nine companies had achieved the growth spurt through organic growth.

Industrial manufacturing companies were chosen to investigate companies creating real growth, new jobs, and welfare. Firms operating in the service sector are often criticized of just transferring jobs from a bigger organisation to a smaller and leaner unit. Many of these companies grow, but their overall contribution to the welfare of society can be questionable. High-growth strategies are concerned with maximising short-term goals, rather than with the creation of growing, economically sustainable, profitable firms (Haltiwanger, Jarmin and Miranda, 2010; Neumark, Wall and Chang, 2010).

TABLE 1. Turnovers (in thousands of euros) in the studied companies between years 2007-2013. Growth spurt year turnover in bold.

\begin{tabular}{|l|l|c|c|c|c|c|c|c|}
\hline COMPANY & Industry & Established & $\begin{array}{l}\text { Number of } \\
\text { employees }\end{array}$ & $\mathbf{2 0 0 9}$ & $\mathbf{2 0 1 0}$ & $\mathbf{2 0 1 1}$ & $\mathbf{2 0 1 2}$ & $\mathbf{2 0 1 3}$ \\
\hline Case A & Metal industry & 1988 & 17 & 1169 & $\mathbf{2 0 4 5}$ & 2690 & 2450 & 2327 \\
\hline Case B & Metal industry & 1954 & 60 & 9135 & 9750 & 12572 & $\mathbf{1 5 2 9 4}$ & 11651 \\
\hline Case C & Metal industry & 2005 & 39 & 4167 & 5816 & $\mathbf{9 5 5 3}$ & 10336 & 9554 \\
\hline Case D & Mechanical engineering industry & 1989 & 34 & 2777 & 2610 & $\mathbf{4 7 2 7}$ & 3961 & 4168 \\
\hline Case E & Electrotechnical industry & 2003 & 21 & 3100 & 3500 & 4126 & 6634 & $\mathbf{1 0 3 9 1}$ \\
\hline Case F & Construction engineering industry & 1989 & 77 & 10796 & 13698 & $\mathbf{1 7 2 4 1}$ & 17603 & 18512 \\
\hline Case G & Construction engineering industry & 2005 & 75 & 5317 & 6782 & $\mathbf{1 0 3 6 9}$ & $\mathbf{1 3 0 3 4}$ & $\mathbf{1 6 1 0 5}$ \\
\hline Case H & Construction engineering industry & 1982 & 41 & 5442 & 4191 & 5887 & 6204 & $\mathbf{8 1 1 3}$ \\
\hline Case I & Producer goods industry & 2008 & 29 & 1642 & 2866 & 3876 & 4062 & $\mathbf{1 0 6 4 7}$ \\
\hline Case J & Sports facility goods & 1991 & 30 & 11893 & 12024 & 11142 & 11723 & $\mathbf{1 6 2 0 0}$ \\
\hline
\end{tabular}

*Case A; year 2007: 1 136, year 2008: 1887 thousands of euros. 


\subsection{Data collection}

An essential feature of theory building is the comparison of the emergent concepts, theory, or hypotheses with the extant literature. This involves asking what is this similar to, what does it contradict, and why. A key to this process is to consider a broad range of literature (Eisenhardt, 1989). To get this far, we have used multiple data sources; archives and field observation, but the hub of this study is the semi-structured interview and real-time processing by those people experiencing the phenomenon. The unit of analysis of this study is a firm, but narrative analysis of the owners/managers in charge was chosen as the methodological approach in this study. The qualitative data works well with the selected theory, but also seemed appropriate for the target group of this study, as narratives can help understand these unique processes.

As people relate narratives on their personal experiences, they also weave, mould and fashion their sense of self in the process (Kenny, Whittle and Willmott 2011, p. 27). One major risk of this practice is being too close to the informant, adopting the informant's view, and losing the higherlevel perspective necessary for theorizing the gathered information (Gioia, Corley and Hamilton, 2012). For further improvement of the quality of our interpretations, we always had a member of our team to adopt an outsider perspective. All the interviewees' were company owners or leaders, and in charge of the operations. Before starting the interviews, the interviewers briefly explained the research, secured the interviewees' permission to record their responses, and guaranteed them anonymity. After the data gathering and initial stages of analysis, we begin cycling between data, dimensions, themes and the previous literature to find out, how our findings confront the existing concepts. With a researcher triangulation we worked together to reach agreement about some the data for arriving at consensual interpretations of the obscure data. This part of the work is characterized by group discussions to reach common understanding among the researchers.

The interviews aimed to isolate the reasons for the growth spurts and the preconditions affecting them. Informants were asked to provide general information on the company and its output and then moved on to investigate research themes described below. The interviewees came from different educational backgrounds and had several years of working experience. The level of education varied from only completing secondary school to completing a university degree. Some of the informants had worked in the same company for their whole career, others in different SMEs, and others in large companies. The interviews were recorded, transcribed, and annotated with a short case history. The unabridged transcriptions of the interviews were used for the final analysis. Once 
the interviews had been conducted, the case histories for each company were written based on their narratives. The focus was on capturing key decisions made before and during the growth spurt period. Critical incidents and the presence of effectual or causal behaviours at each event were thoroughly investigated, compared and cross-checked using the measures introduced by Chandler et al. (2011).

The interviewees were asked to outline in their own words (narrative) the significant events that had occurred in the company during the years of moderate growth prior to the growth spurt, and which factors they thought might have influenced the growth spurt. Subsequently, the interviewer asked questions to elicit certain themes that the interviewee had not raised spontaneously. The questions were based on the subdimensions of effectuation defined by Chandler et al. (2011); experimentation, affordable loss, flexibility, and in common with causation, pre-commitments were used as the themes of the research interviews. With its 87 citations in only five years period, Chandler et al (2011) can be stated as the most widely acknowledged conceptual framework.

\section{Findings}

The findings strengthen the previous findings that logics of effectuation seem to suit the studied small and medium-sized companies. That is particularly because such firms tend to have limited resources, a propensity to focus on one or a few projects, and an ability to retain a flexible approach to their business. The study period covered a turbulent time when the entire Eurozone faced extensive changes and dealt with a recession in the years 2009-2013. Nevertheless, this period appears to have been more profitable for companies that successfully reacted to changes in their operating environments and adapted their activities to reflect the situational changes. The ability to do things differently from competitors also emerged in this study. The companies that achieved a growth spurt in this period appeared to have gained a competitive advantage by committing their clients to participate in development work and developing their service processes around industrial products.

\subsection{Focus on short terms experiment to identify opportunities versus prediction of the future}

Major changes in the companies' operational environment and the difficulty of predicting those changes were highlighted in this study. Despite the fact that the majority of the studied companies 
had prepared a strategy, its practical implementation had proved extremely difficult. Customerorientation and quickly responding to demand in rapidly changing situations were perceived as methods for pursuing business growth. The majority of the studied companies (7/10) seemed to rely on the resources available at the starting point, that is, they followed the logic of effectuation. In three of the ten companies, the approach used could be said to be proceeding towards the goal, which indicates the use of the logic of causation.

We set out objectives of what we want to be, but the ways to do that were completely turned on their heads. We were supposed to focus on the maintenance industry, but this pretty quickly became project construction... partly due to the clients we had at the time. One thing I've learned from the world of business is that you should never live by a certain formula, but you always have to live by your client, the client's needs, where the money comes from (Effectuation, case company I)

Small and medium-sized companies' resources are more limited than those of large firms. They lack the organisational and marketing capabilities of their larger counterparts, but they enjoy greater flexibility (Van de Vrande et al., 2009; Berends et al., 2014).

There was a goal. When the recession started in 2009, our turnover decreased and from that point on the aim was to start searching for where to find growth and the alternatives we thought about were expansion through product development or corporate acquisitions. In that sense we have been goal-oriented, seeking growth all the time and we still continue this. (Causation, Case H)

\subsection{Affordable loss versus aiming at maximization of expected returns}

The concept of high risk taking is extremely difficult to define; for one company, a big investment may not be a risk, while for another company it is. In this study, a high risk level was determined as occurring when the risk could endanger the continuity of the entire company operations. Only one of the companies was identified by its representative as having taken such a risk. In this case, the risk taking can be said to have followed the logic of causation. In contrast, the remaining nine out of the ten companies swore by taking controlled risks, that is, following the logic of effectuation. This correlates with previous research knowledge; entrepreneurial companies tend to take moderate 
risks, those that will not endanger the operations of the company (Sarasvathy, 2001). This fits well with the characteristics of small firms, and in particular that their limited resources lead them to focus on one or a few projects, and their flexibility (Berends et al., 2014).

Well, it's probably been more on the controlled side. Of course, we did make investments of over one million euros last summer. They really are big investments, but when looking at the size of the company, it's still on the controlled side. (Effectuation, case company B)

Case company B's turnover is more than fifteen million EUR, so the one million EUR investment can be considered moderate risk taking, which is associated with effectuation.

Yes, we have been taking risks...of course now that the world hasn't gone the way we thought it would go, that there would be growth, we have now been more restricted and more careful, so right now we are minimising risks. (From causation towards effectuation, case company G)

Most recent research findings confirm expectations that effectual and causal logics can work simultaneously (Sitoh et al., 2014; Dutta, et al., 2015; Lingelbach, Sriram and Mercha, 2015; Reymen et al., 2015). In this case, the causation oriented case company $G$ adopted a high risk approach in line with its strategy. That risk has materialised and the company has accordingly been forced to change its risk taking approach to a more moderate from, a move reflecting a transition from causation logic towards effectuation.

4.3.Emphasis on pre-commitments and strategic alliances to control the future versus competitive analyses to predict the future, and

Building strategic alliances has been connected to effectuation in previous research, whereas competitor analyses and making choices based on those are a central part of the causation approach. While some of the studied companies did follow and analyse the operations of their competitors, they still focused more on their own activities and enhancing such activities based on feedback obtained from clients, distributors, manufacturers and other stakeholders. 
You don't have to be best friends with the competitors, but you do have to get along with them. We have good relationships with our competitors, it is better to know the competition than not to know them. You have to follow the competitors enough to know what they know and can do so that you know where you're going, what's coming and so on. A lot of time you get this information when you build an alliance with them and you get good relationships with suppliers and other stakeholders. (Effectuation, Case company J)

Out of the ten companies, only one had used causational competitor analyses and followed a clear challenger strategy to achieve growth in its operations. This company was facing major economic challenges at the time of the interview. Its chosen strategy had not proven to be the most fruitful in the turbulent situation of a declining market. Indeed, at the time of the interview, the company operations were being redirected to include building more partnerships, by pursuing procurement cooperation and subcontracting with the firm's main competitor, for example.

The market was and has been fairly focused. In practice there has been one big firm that has been totally dominating the market and that's kind of the market which our company targeted...Clearly the market has been looking for another worthwhile player. (Causation, Case company $G$ )

In this case, the chosen strategy was clearly to challenge the market leader. Case company G managed to grow, but its strategy has also brought liquidity issues. The general economic conditions have not developed favourably, and the company seems to have been forced to forge an alliance with the market leader. This is indicative of the company's shift towards the effectuation approach, after strong evidence of its use of the causation form.

4.4. Exploitation of the environmental contingencies by remaining flexible versus exploitation preexisting capabilities and resources

Flexibility is a key strength of small firms (Fiegenbaum and Karnani, 1991), they are relatively unfettered by internal bureaucracy and are often managed by an owner/director who is able to take key decisions quickly. They enjoy efficient and informal internal communication patterns, and tend to develop strong networks with their customers. The growth in all of the studied companies appears to be based at least to some extent on the utilisation of changes in the operating 
environment. The capability of companies to benefit from changes in their operating environment can be considered one of the main factors explaining the growth spurts. Taking advantage of changes in the environment is an essential part of effectuation theory, and thus supports the idea of effectuation theory as a contributor to the companies' growth processes.

The characteristics of SMEs enable a rapid response to market changes (Chandy and Tellis, 2000; Verhees and Meulenberg, 2004), often resulting in differentiated products for markets (Kogut, 1997; Qian and Li, 2003). The size of the studied companies made them easily manageable, and the company owners usually acted as the company's operative management, which allowed decisionmaking to be less hierarchical than in larger counterparts. It also emerged that the flow of information (e.g. regarding customer feedback) was smooth in the companies, and they were able to quickly respond to feedback on their activities. On the other hand, half of the companies considered the role of previously acquired knowledge as at least somewhat important for the success of the company, and therefore there was evidence of some planned activities having been implemented. The companies particularly attempted to predict future changes in the field, an activity in line with causation theory.

We have a possibility to react quickly. If we hear from the field that something is what is needed, we are going to react to that. There is none of this sort of hierarchy there to make things more difficult. (Effectuation, Case company I)

It doesn't matter if the market is going up or down, there's always a possibility to find new clients. There's just a different reason for it. If we just work away as usual, no one is going to need to change suppliers. If potential clients are doing worse financially, the first thing they are going to do is to search for alternatives. (Effectuation, Case company C)

This study strengthens the findings of previous literature, which show subdimensions of effectuation suit entrepreneurial operating culture of the small and medium sized companies. Findings indicate the usage of both logics; effectuation and causation, but effectuation seems to have been the dominant approach in nine of the ten companies. Only one of the companies can be said to have been following the operating principles of causation. Three out of ten companies seemed to implement both effectuation and causation logics simultaneously. The causation ensures that the venture stays focused and predicts what is predictable, while effectuation allows responding 
flexibly to changes in operation environment (Dew, Sarasvathy and Wiltbank, 2011; Dew et al 2009; Sarasvathy, 2008). Berends, Jelinek, Reymen and Stultiens (2014)

TABLE 2. Subdimensions of effectuation and causation and their prevalence in the companies.

(E indicates effectuation as the dominant factor, while $\mathrm{C}$ indicates causation).

\begin{tabular}{|l|l|l|l|l|l|l|l|l|l|l|}
\hline Approach / Companies & A & B & C & D & E & F & G & H & I & J \\
\hline $\begin{array}{l}\text { Focus on short terms experiment to identify opportunities, E } \\
\text { versus goal has been determined to predict the future, C }\end{array}$ & E & E & E & E & E & E & C & C & C & E \\
\hline $\begin{array}{l}\text { Affordable loss, E } \\
\text { versus maximization of expected returns, C }\end{array}$ & E & E & E & E & E & E & C & E & C & E \\
\hline $\begin{array}{l}\text { Pre-commitments and strategic alliances to control the } \\
\text { future, E versus competitor analysis, C }\end{array}$ & E & E & E & E & E & E & C & E & E & E \\
\hline $\begin{array}{l}\text { Exploitation of the environmental contingencies, E } \\
\text { versus exploitation pre-existing capabilities and resources, C }\end{array}$ & E & E & E & E & E & E & C & E & E & E \\
\hline
\end{tabular}

Factors explaining such a strong prevalence of effectuation included: the studied companies were entrepreneurial, small and medium-sized, primarily managed by their owners, and had fairly informal decision-making. The timing of this study being 2009-2013 was a further significant factor. This was a period when the business environment was in a turbulent state. The changes in business environment were immensely unpredictable; this explaining factor emerged in a number of the interviews. The interviewees reported that it was difficult to make long-term plans due to radical changes in the operating environment. They had to be constantly prepared to react to changes in the operational environment and to act in whichever way was required by those changes.

Transition from a product-centred to a client-centred approach was one of the most prevalent findings in this study. The industrial production companies sought a competitive advantage by becoming more customer-oriented. The studied companies listened to the market through feedback acquired from clients and reacted to the changes demanded by the market. The topic of networking emerged in every narrative. For most of the companies, this was a conscious choice and a means to seek competitive advantage in product development, know-how and, for instance, procurement of material. Networking was also perceived as a way to influence the field and its development, and as with transitioning towards service provision, as a means to legislate for the future (Sarasvathy, 2001). Only one interviewee assessed their firm to have taken a risk of such magnitude that it could have negatively affected the company's future operations. The willingness to take risks of such a 
magnitude is linked to the causation theory in the literature. In contrast, nine out of ten interviewees swore by taking controlled risks, which in turn is an indication of the use of an approach following the logic of effectuation (Sarasvathy, 2001).

\section{Implications and limitations}

This study has four theoretical implications. First, the study expands the scope of effectuation research from its prior primary focus on new ventures and start-ups to include established companies as a suitable context. In doing so, the study has implications that effectuation research and development output needs to be taken to include established companies, which were neglected in effectuation research for many years. Established companies have the potential to take a growth leap and become growth companies, when using logics of effectuation and causation. Second, we strengthen the recent findings that effectuation and causation can work simultaneously in the same company. This observation follows the trend in the current effectuation literature, where both processes are found used complimentarily (Sitoh, Pan, and Yu, 2014; Van de Vrande, De Jong, Coviello and Joseph, 2012). Effectuation and causation processes can coexist and that they are configured in specific ways at different phases of company's lifecycle. Third, the findings strengthen the previous literature, where effectuation is considered a practical approach in turbulent and dynamic situations in which it is difficult to predict the future (Sarasvathy, 2001; Fisher, 2012; Dutta et al., 2015). As the companies examined in this study were small and medium-sized, their size allowed this flexible management. Rapid and straightforward decision-making was also evident; small firms can adapt more readily than bigger firms, which is previously found in literature (Alvarez and Barney, 2005; McMullen and Shepherd, 2006). Fourth, there is relatively little previous literature combining effectuation to business growth. In a systematic literature review we found seven papers, which had both concepts in the key words or title, but found no studies combining an investigation of these two concepts in the context of established companies. We contribute to the effectuation literature by connecting all these elements. Additionally, previous research has suggested that when framing decisions, the experienced entrepreneurs tend to adopt an effectual logic while novices tend to use logics of causation (Dew et al. 2009, Sarasvathy, 2008). All the informants in our study can be described as experienced leaders, so this factor supports the previous literature. 
Our study has several managerial implications. First, we highlight that companies which selected a customer-oriented approach seem to have achieved success and growth regardless of the recession in their field of operations. These findings are in line with Coviello and Joseph (2012) whose findings indicate that successful innovators tend to engage with customers. Building strategic alliances and networking emerged as one of the most common factors in the studied companies. Cooperation occurs with clients and suppliers and also with competitors. Second, our study indicates that owner-managers are leveraging new information to connect a new technology with customers so as to deliver a better customer value proposition. Third, the study shows that entrepreneurs' abilities to leverage contingencies arising from new information are critical in promoting business growth. Networking and building strategic alliances were actions that emerged in all of the narratives gathered, and can thus be considered a shared factor in identifying opportunities for business growth.

Like any other study, our research has certain limitations, particularly regarding to the sample and measurements. As a result of re-analyzing the data, we came to the conclusion that mixed methods with quantitative data would provide more generalized information to this phenomenon. Even though, qualitative research should be able to stand on its own, how do we know that we haven't just made up an interesting conclusion of the gathered information? Well we cannot tell that for sure. Qualitative research still suffers the criticism that it does not absolutely justify its contentions and contribution. Skepticism for the qualitative research is engaging in unconventional theorizing on the basis of rather vague evidence. The more systematic approach of data gathering would visualize the phenomenon in a more rigorous way. As a conclusion, the findings of this study support the previous literature, but are to be considered generally weak, due to the lack of transparency and data triangulation (Gioa, Corley and Hamilton, 2012:18).

\section{Acknowledgement}

This research project has been funded by the European Social Fund and that support is gratefully acknowledged. 


\section{References}

Alsos, G. A., Clausen, T.H. and Solvoll, S., (2014). Towards a better measurement scale of causation and effectuation. Paper presented at Academy of Management Meeting, Philadelphia, PA.

Alvarez S. and Barney J. (2005). "How do entrepreneurs organize firms under conditions of uncertainty?”, Journal of Management, Vol. 31 No. 5, pp. 776-793.

Alvarez, S.A. and Busenitz, L. W. (2001). “The entrepreneurship of resource-based theory”, Journal of Management, Vol. 27, pp.755-775.

Ansoff, H.I. (1965). Corporate strategy: an analytic approach to business policy for growth and expansion. New York: McGraw-Hill.

Arend, R., Saroogh, H. and Burkemper, A. (2015). "Effectuation as ineffectual? Applying the 3E Theory assessment framework to a proposed new theory of entrepreneurship", Academy of Management Review, Vol. 40 No. 1, pp. 830-851.

Audretsch, D. B. (1995). "Firm profitability, growth, and innovation", Review of Industrial Organization, Vol.10 No.5, pp.579-588.

Barney, J. (1991). Firm resources and sustained competitive advantage. Journal of Management, Vol 17 (1), pp. 99-120.

Baron, R. A. (2009). Effectual versus predictive logics in entrepreneurial decision making: Differences between experts and novices: Does experience in starting new ventures change the way entrepreneurs think? Perhaps, but for now, "Caution” is essential. Journal of Business Venturing, Vol. 24, (4) pp. 310 -315

Barron, D. (1999). “The structuring of organizational populations”, American Sociological Review, Vol. 64, pp. 421-445.

Batt, R. (2002). "Managing customer services: Human resource practices, quit rates, and sales growth”, Academy of Management Journal, Vol. 45, pp. 587-597. 
Baum, R.J., Locke, E.A. and Smith, K.G. (2001). “A multidimensional model of venture growth”, Academy of Management Journal, Vol. 44, pp. 292-303.

Berends, H., Jelinek, M., Reymen, I. and Stultiëns, R. (2014). "Product innovation processes in small firms: Combining entrepreneurial effectuation and managerial causation”, Journal of Product Innovation Management, Vol. 31 No. 3, pp. 616-635.

Brettel, M., Mauer, R, Engelen, A. and Küpper, D. (2012). “Corporate effectuation: Entrepreneurial action and its impact on R\&D project performance”, Journal of Business Venturing, Vol. 27, pp. 167-184.

Brinckmann, J., Grichnik, D. and Kapsa, D. (2010). Should entrepreneurs plan or just storm the castle? A meta-analysis on contextual factors impacting the business planning-performance relationship in small firms. Journal of Business Venturing, Vol. 25, pp. 24-40.

Chandler, G., DeTienne, D., McKelvie, A. and Mumford, T. (2011). “Causation and effectuation processes: a validation study”, Journal of Business Venturing, Vol. 26, pp. 375-390.

Chandy, R.K. and G.J. Tellis. (2000). “The incumbent's curse? Incumbency, size, and radical product innovation”, Journal of Marketing, Vol. 64 No. 3, pp. 1-17.

Chiles, T.H., Bluedorn, A.C. and Gupta, V.K. (2007). "Beyond creative destruction and entrepreneurial discovery: A radical Austrian approach to entrepreneurship”, Organization Studies, Vol. 28, pp. 467-493.

Connor, K. (1991). “A historical comparison of resource-based theory and five schools of thought within industrial organization economics”, Journal of Management, Vol. 17, pp. 121-154.

Coviello, N.E. and Joseph, R.M. (2012). “Creating major innovations with customers: Insights from small and young technology firms”, Journal of Marketing, Vol. 76 No. 6, pp. 87-104.

Covin, J.G. and Slevin, D.P. (1989). "Strategic management of small firms in hostile and benign environments”, Strategic Management Journal, Vol. 10, pp.75-87. 
Davidsson, P. (1989). "Entrepreneurship - and after? A study of growth willingness in small firms”, Journal of Business Venturing, Vol. 4, pp. 211-226.

Davidsson, P., Kirrchoff, B, Hatemi J,A. and Gustavsson, H., (2002). "Empirical analysis of business growth factors using Swedish data”, Journal of small business management, Vol. 40 No. 4, pp. 332-349.

Dew, N., Read, S., Sarasvathy, S.D. and Wiltbank, R. (2009). "Effectual versus predictive logics in entrepreneurial decision-making: differences between experts and novices”, Journal of business venturing, Vol. 24, pp. 287-309.

Dew N, Read S, Sarasvathy SD and Wiltbank R. (2011). "On the entrepreneurial genesis of new markets: effectual transformations versus causal search”, Journal of Evolutionary Economics, Vol. 21 No. 2, pp. 231-253.

Dew, N. and Sarasvathy, S. (2007). "Innovations, Stakeholders and Entrepreneurship”, Journal of Business Ethics, Vol. 74, pp. 267-283.

Dutta, D.K., Gwebu K.L. and Wang, J. (2015). "Personal innovativeness in technology, related knowledge and experience, and entrepreneurial intentions in emerging technology industries: a process of causation or effectuation?”, International Entrepreneur Management Journal, Vol. 11, pp. 529-555.

Eisenhardt, K.M. (1989). Building Theories of Case Study Research. The Academy of Management Review. Vol. 14, pp. 532-550.

Fiet, J.O., Norton, W.I. and Van Clouse G.H. (2012). "Search and discovery by repeatedly successful entrepreneurs”, International Small Business Journal, Vol. 31 No. 8, pp. 890-913.

Fiegenbaum, A., and Karnani, A. (1991). “Output flexibility: A competitive advantage of small firms”, Strategic Management Journal, Vol. 12 No. 2, pp. 101- 14. 
Fisher, G. (2012). "Effectuation, causation, and bricolage: a behavioral comparison of emerging theories in entrepreneurship research", Entrepreneurship Theory and Practice, Vol. 36 No. 5, pp. 1019-1051.

Fischer, E. and Reuber, R. (2011). Social interaction via new social media: (How) can interactions on Twitter affect effectual thinking and behavior? Journal of Business Venturing, 26, pp. 1-18.

Gabrielsson, P. and Gabrielsson, M. (2013). A dynamic model of growth phases and survival in international business-to-business new ventures: The moderating effect of decision-making logic, Industrial Marketing Management, Vol. 42, pp. 1357-1373.

Gioia. Corley and Hamilton (2012) Seeking Qualitative Rigor in Inductive Research: Notes on the Gioia Methodology, Organizational Research Methods 16 (1) 15-31.

Haltiwanger, J. C., Jarmin, R. S. and Miranda, J. (2010). "Who creates jobs? Small versus large versus young”, National Bureau of Economic Research, Working Paper 16300.

Helmersson, H. and Mattsson, J. (2013). “Text-analytic measurement of effectuation and causation orientations among small and global business managers”, Qualitative and Quantitative research, Vol. 47, pp. 3493-3507

Jennings, D.F. and Lumpkin, J.R. (1989). "Functioning modeling corporate entrepreneurship: An empirical integrative analysis”, Journal of Management, Vol. 15 No. 3, pp. 485-502.

Kalinic, I., Sarasvathy, S. and Forza, C. (2014). "Expect the unexpected: Implications of effectual logic on the internationalization process”, International Business Review, Vol. 23, pp. 635-647.

Kenny, K., Whittle, A., and Willmott, H. (2011). Understanding Identity and Organizations. London: SAGE Publications.

Ketchen, D.J., Thomas, J.B. and Snow, C.C. (1993). “Organizational configurations and performance: A comparison of theoretical approaches”, Academy of Management Journal, Vol. 36, pp. 1278-1313. 
Knight, F.H. (1921). Risk, uncertainty and profit, Houghton Mifflin, New York.

Kuratko, D. F., Hornsby, J. S. and Goldsby, M. G. (2004). "Sustaining corporate entrepreneurship: A proposed model of perceived implementation/outcome comparisons at the organizational and individual levels”, International Journal of Entrepreneurship and Innovation, Vol. 5 No. 2, pp. 7789.

Leitch, C., Hill, F. and Neergaard, H. (2010). “Entrepreneurial and Business Growth and the Quest for a "Comprehensive Theory”: Tilting at Windmills”, Entrepreneurship Theory and Practice, Vol. 34 No. 2, pp. 249-260.

Lingelbach, D., Sriram, V., Mersha, T. and Saffu, K. (2015). “The innovation process in emerging economies. An effectuation perspective”, Entrepreneurship and innovation, Vol. 16 No. 1, pp. 5-17.

Lumpkin, G. and Dess, G. (1996). "Clarifying the entrepreneurial orientation construct and linking it to performance”, The Academy of Management Research, Vol. 21 No. 1, pp. 135-172.

March, J. (1982). “Theories of choice and making decisions”, Society, Vol. 20, pp. 29-39.

March, J. (1991). Exploration and exploitation in organizational learning. Organization Science, 2 (1), pp 71-87.

McKelvie, A. and Wiklund, J. (2010). “Advancing firm growth research: a focus on growth mode instead of growth rate”, Entrepreneurship Theory and Practice, Vol. 34 No. 2, pp. 261-288.

McMullen, J.S. and Shepherd D.A. (2006). "Entrepreneurial action and the role of uncertainty in the theory of the entrepreneur”, Academy of Management Review, Vol. 31 (1), pp. 131-152.

Mintzberg, H. and McHugh, A. (1985). "Strategy formation in an adhocracy", Administrative Science Quarterly, Vol. 30, pp. 160-197.

Mintzberg, H. (1978). "Patterns in strategy formation”, Management Science, Vol. 24 No. 9, pp. 934-948. 
Murphy, G. B., Trailer, J. W. and Hill, R. C. (1996). Measuring performance in entrepreneurship research, Journal of Business Research, Vol. 36, pp. 15-23.

Neumark, D., Wall, B. and Chang, J. (2010). “Do Small Businesses Create More Jobs? New Evidence From the National Establishment Time Series. National Bureau of Economic Research, Working Paper 13818.

Parker, S. C., Storey, D. and Witteloostuijn, A. (2010). "What happens to gazelles? The importance of dynamic management strategy”, Small Business Economics, Vol. 35, pp. 203-226.

Perry, J., Chandler, G. and Markova, G. (2012). "Entrepreneurial effectuation: A review and suggestions for future research”, Entrepreneurship Theory and Practice, Vol. 36 No. 4, pp. 837861.

Phelps, R., Adams, R. and Bessant, J. (2007). "Life cycles of growing organizations: Are view with implications for knowledge and learning”, International Journal of Management Review, Vol. 9, pp. 1-30.

Piekkari, R. and Welch, C. (2011). Rethinking the case study in international business and management research, Edward Elgar, Cheltenham, UK.

Pongracic, I. (2009). Employees and entrepreneurship: Coordination and Spontaneity in NonHierarchical Business Organizations, Edward Elgar, Cheltenham, UK.

Qian, G. and Li L., (2003). "Profitability of small-and-medium-sized enterprises in high-tech industries: The case of the biotechnology industry”, Strategic Management Journal, Vol. 24 No. 9, pp. 881-87.

Read, S., Sarasvathy, SD., Dew, N. and Wiltbank, R. (2016). Response to Arend, Sarooghi, and Burkemper (2015). Cocreating effectual entrepreneurship research. Academy of Management Review, vol. 41, no. 3, pp. 528-536. 
Reymen, I., Andries, P., Berends, H., Mauer, R., Stephan, U. and Van Burgh, E. (2015). "Understanding dynamics of strategic decision making in venture creation: A process study of effectuation and causation”, Strategic Entrepreneurship Journal, Vol. 9, pp. 351-379.

Sarasvathy, S. (2001). "Causation and effectuation: towards a theoretical shift from economic inevitability to entrepreneurial contingency”, Academy of Management Review, Vol. 26, pp. 243263.

Sarasvathy, S. (2008). Effectuation: Elements of Entrepreneurial Expertise, Edward Elgar Cheltenham, UK.

Sarasvathy, S., Kumar, K., York, J., and Bhagavatula, S. (2014). An effectual approach to international entrepreneurship: overlaps, challenges, and provocative possibilities. Entrepreneurship Theory and Practice, Vol. 38 Issue 1, pp. 71-93.

Schmelter, R., Mauer, R., Borsch, C. and Brettel, M. (2010). "Boosting corporate entrepreneurship through HRM: Evidence from German SMEs”, Human Resource Management, Vol. 49 No. 4, pp. 715-741.

Short, J.C., Payne, G.T. and Ketchen, D.J. (2008). "Research on organizational configurations: Past accomplishments and future challenges”, Journal of Management, Vol. 22, pp. 9-24.

Sitoh, M.K., Pan, S.L. and Yu, C.Y. (2014). "Business models and tactics in new product creation: The interplay of effectuation and causation processes", Transactions on Engineering Management, Vol. 61 No. 2, pp. 213-224.

Storey, D. J. (1996). The Ten Percenters, Deloitte and Touche, London, UK.

Svensrud, E. and Åsvoll, H. (2012). Innovation in large corporations: A development of the rudimentary theory of effectuation. Academy of Strategic Management Journal, Vol 11, No. 1, pp. 59-89. 
Van de Vrande, V., De Jong, J.P., Vanhaverbeke, W. and De Rochemont, M., (2009). “Open innovation in SMEs: Trends, motives and management challenges”, Technovation, Vol 29 No. 6, pp.423-437.

Weick, K. (1979). The Social Psychology of Organizing. 2nd ed., Addison-Wesley, Reading MA.

Werhahn, D., Mauer, R., Flatten, T. and Brettel, M. (2015). "Validating effectual orientation as strategic direction in the corporate context”, European Management Journal, Vol. 33, pp. 305-313.

Verhees, F. and Meulenberg. M., (2004). "Market orientation, innovativeness, product innovation, and performance in small firms”, Journal of Small Business Management, Vol. 42 No. 2, pp. 134-54.

Wiklund, J. (1999). "The sustainability of the entrepreneurial orientation - performance relationship”, Entrepreneurship Theory and Practice, Vol. 24, pp. 37-48.

Wiklund, J., Patzelt, H. and Shepherd, D. (2009). "Building an integrative model of small business growth”, Small Business Economy, Vol. 32, pp. 351-374.

Wiltbank, R., Dew, N. Read, S. and Sarasvathy, S. (2006). "What to do next? The case for nonpredictive strategy”, Strategic Management Journal. Vol. 27, pp. 981-998. 


\section{APPENDIX}

\section{Focused interview form, effectuation (translated from Finnish)}

\section{General}

For each central theme, the interviewee aims to probe into the themes of the study and seek explanations for how planned and unplanned incidents and reactions to them have affected the growth spurt of the company.

A case history will be written on each company and its growth process, depicting the events that took place in the company during the examined period. The purpose is not to write a similar narrative for every company (or to ask the same focused questions), but to determine which were the key incidents occurring and choices made in the company. The purpose is also not to make any choices beforehand on the key issues resulting in the growth of the company, but to instead emphasise the unique narrative of each company. The case histories will be analysed together, aiming at recognising the emergence of central themes and the contexts for this.

The questions A-D below are to be asked of all interviewees. Question D supports writing the case history. The D question also includes a list of the themes of this study, whose significance on the growth/change that was achieved in the company should be investigated. These themes (1-6) have been explained in more detail in the following pages of the form.

\section{A. The name of the company and the interviewee}

- and the year since which the person has worked for the company?

\section{B. What are the current products/services provided by the company?}

- have there been any changes to the products/services since the year XXXX?

\section{Who are the current clients of the company?}

- have there been any changes to the clients since the year XXXX? 


\section{THERE WAS A GROWTH SPURT IN YOUR COMPANY IN THE YEAR XXXX. WHICH FACTORS DO YOU THINK CONTRIBUTED TO THIS AND WHICH SIGNIFICANT ISSUES/INCIDENTS WOULD YOU LIKE TO RAISE?}

\section{IF YOU WERE TO PROVIDE A NARRATIVE ON THE EVENTS LEADING TO THE GROWTH SPURT, BEFORE AND AFTER, WHAT WOULD YOU SAY?}

Research themes based on which more detail may be requested;

\section{Experimentation focus on short terms experiment to identify opportunities versus prediction of the future.}

Was the goal determined beforehand or did the company seize an opportunity that arose?

How did the chosen growth approach influence the resources later available for the company (e.g. financial resources)?

How did the company obtain the additional capacity required by the growth: increasing the company's own resources (e.g. the number of staff), making operations more efficient (e.g. with automatisation) or by utilising the resources of others (by building networks)?

What does strategy mean to you?

With whom do you discuss strategy (or issues influencing the future of the company)?

What kind of a role does st aff have in planning and implementing the firm's strategy?

What are the issues raised when discussing the company's future, i.e. the strategic issues?

What kind of routines do you have in relation to the company's strategy work?

When does the strategy work take place? (annually? continuously? when there is time for it?)

Does your strategy work have physical outcomes? If you answered 'yes', what are these? (report, length? Powerpoint?)

Could you explain the forms of unofficial strategy work in your company?

Has the way in which you conduct strategy work in your company changed in some way over the years? How?

Do your clients or suppliers participate in the strategy work in any way?

Can you say that your company has followed the strategy that you have formulated?

What is the meaning of strategic planning for the growth and success of your company?

\section{Affordable loss versus maximization of expected returns}


When does the company particularly aim to avoid risk, when is risk taking acceptable (the nature of the outside environment, context specificity)?

When and in what kinds of situations (environmental conditions, the company's situation, the entrepreneur's situation) have risks been taken in the company?

How great a risk is acceptable in the company when the outcome pursued is very tempting? Can the risk be so high that the company's finances would be seriously jeopardised if it materialised?

Which is more important, keeping the risk at a manageable level and possibly at the same time settling for smaller financial outcomes, or to pursue bigger profits with greater risks?

If the risk taking has resulted in some sort of a crisis, how has this affected your later decisions? Are crises considered learning experiences or failures?

\section{Emphasis on pre-commitments and strategic alliances to control the future versus competitive analyses to predict the future}

How does networking with different stakeholders (suppliers, clients, competitors etc.) affect your operations?

How openly is information shared between the different stakeholders?

How do you determine the expectations of clients? How do you prepare for changes in clients' needs? (are clients involved in product development, or marketing etc.)

Do you engage clients and other partners in cooperation in joint activities and how do you accomplish this? (influencing the future)

How do you discover your competitors' operations and react to them?

How is information about clients' expectations and competitors shared within the company between different workers? How is this information taken into account in product and service development?

\section{Exploitation of the environmental contingencies by remaining flexible versus exploitation pre-existing capabilities and resources}

Has the company succeeded in utilising changes that have occurred in the operating environment? If it has, how has this been accomplished?

How are new actions established in the company's approaches?

Have you noticed a need to provide more training for the staff as the company has grown bigger and developed? 
Has the company acquired information about the industry and the market? How has the company succeeded in utilising this information? Does information acquisition have an important role? (predicting the future)

What kind of systems (information, client management, production management systems) are in use in the company and when were they adopted?

Which financial indicators are monitored (e.g. financial statements, return on capital, indebtedness, liquidity)? Are different issues monitored in different situations?

Has the company considered it necessary to produce things differently than has traditionally been done in the field? Has this produced a competitive advantage? (bricolage)

Is there a need for anticipatory, routine-breaking and experience-based activities in the company's decision-making? Could you provide an example of an incident where these were needed? (improvisation) 